\title{
ORIGINAL
}

\section{Inter-country variability over time in the mortality of mechanically ventilated patients}

Oscar Peñuelas ${ }^{1}$, Alfonso Muriel2 ${ }^{2}$, Victor Abraira² ${ }^{2}$ Fernando Frutos-Vivar ${ }^{1 *}{ }^{*}$, Jordi Mancebo ${ }^{3}$, Konstantinos Raymondos ${ }^{4}$, Bin Du ${ }^{5}$, Arnaud W. Thille ${ }^{6}$, Fernando Ríos ${ }^{7}$, Marco González ${ }^{8}$, Lorenzo del-Sorbo ${ }^{9}$, Niall D. Ferguson ${ }^{9}$, Maria del Carmen Marín ${ }^{10}$, Bruno Valle Pinheiro ${ }^{11}$, Marco Antonio Soares ${ }^{12}$, Nicolas Nin ${ }^{13}$, Salvatore M. Maggiore ${ }^{14}$, Andrew Bersten ${ }^{15}$, Pravin Amin ${ }^{16}$, Nahit Cakar ${ }^{17}$, Gee Young Suh ${ }^{18}$, Fekri Abroug ${ }^{19}$, Manuel Jibaja ${ }^{20}$, Dimitros Matamis ${ }^{21}$, Amine Ali Zeggwagh ${ }^{22}$, Yuda Sutherasan ${ }^{23}$, Antonio Anzueto ${ }^{24}$ and Andrés Esteban ${ }^{1}$

(c) 2020 Springer-Verlag GmbH Germany, part of Springer Nature

\begin{abstract}
Purpose: Variations in clinical characteristics and management and in the mortality of mechanically ventilated patients have not been sufficiently evaluated. We hypothesized that mortality shows a variability associated with country after adjustment for clinical characteristics and management.
\end{abstract}

Methods: Analysis of four studies carried out at 6-year intervals over an 18-year period. The studies included 26,024 patients (5183 in 1998, 4968 in 2004, 8108 in 2010, and 7765 in 2016) admitted to 1253 units from 38 countries. The primary outcome was 28-day mortality. We performed analyses using multilevel logistic modeling with mixed-random effects, including country as a random variable. To evaluate the effect of management strategies on mortality, a mediation analysis was performed.

Results: Adjusted 28-day mortality decreased significantly over time (first study as reference): 2004 : odds ratio 0.82 (95\% confidence interval [Cl] 0.72-0.93); 2010: 0.63 (95\% Cl 0.53-0.75); 2016: 0.49 (95\% Cl 0.39-0.61). A protective ventilatory strategy and the use of continuous sedation mediated a moderate fraction of the effect of time on mortality in patients with moderate hypoxemia and without hypoxemia, respectively. Logistic multilevel modeling showed a significant effect of country on mortality: median odds ratio (MOR) in 1998: 2.02 (95\% Cl 1.57-2.48); in 2004: 1.76 (95\% Cl 1.47-2.06); in 2010: 1.55 (95\% Cl 1.37-1.74), and in 2016: 1.39 (95\% Cl 1.25-1.54).

Conclusions: These findings suggest that country could contribute, independently of confounder variables, to outcome. The magnitude of the effect of country decreased over time.

Clinical trials registered with http://www.clinicaltrials.gov (NCT02731898).

Keywords: Mechanical ventilation, Outcome, Variability, Epidemiology, Mortality

\section{Introduction}

The management of mechanically ventilated patients has improved in recent years with the incorporation of

\footnotetext{
*Correspondence: fernando.frutos@salud.madrid.org

${ }^{1}$ Hospital Universitario de Getafe, Centro de Investigación en Red de Enfermedades Respiratorias (CIBERES), Carretera de Toledo km 12, 500 28905 Madrid, Spain

Full author information is available at the end of the article
}

strategies aimed at preventing or reducing ventilatorinduced lung injury: use of non-invasive positive-pressure ventilation (NPPV) [1-3], a lung-protective strategy [4-6], titration of positive end-expiratory pressure [7], prone positioning [8], and neuromuscular blocking agents [9], and at decreasing the duration of mechanical ventilation through the reduced use of sedatives [10, 11] and the early identification of patient readiness to breathe unassisted [12]. Some of these interventions

\section{至 Springer}


which initially focused on the management of patients with acute respiratory distress syndrome now appear to be substantially applicable to all mechanically ventilated patients [6, 13]. Previous observational data [14-16] have shown that short-term mortality of mechanically ventilated patients has decreased over time. Nevertheless, several aspects in the management of critically ill patients have been shown to differ across intensive care units (ICUs) and countries, leading to considerable clinical variability [17].

Variability in clinical practice is a current and controversial topic, which is of interest not only to clinicians, but also to health administrators and patient advocates. Some variations may be explained by the characteristics of individual patients or by differences in the ability of doctors who rely too much on subjective judgement. However, unwarranted clinical variability may exist, defined as variations in patient outcomes that cannot be explained by the patient's underlying illness or patient care based on evidence-based medicine [18]. The existence of unwarranted variability may have a negative impact on quality of care and clinical outcomes [19]. Geographical variability in outcome has been reported in several conditions such as ischemic heart disease [20, 21], cancer [22-24], and cardiac arrest [25]. However, the geographical or inter-country variability in mortality in critically ill patients has been little evaluated.

In this study, we estimate the inter-country variability in the outcomes of mechanically ventilated patients through the analysis of four international observational studies carried out at 6-year intervals from 1998 to 2016. We hypothesized that, after adjustment for variables related to patient management and clinical characteristics, mortality would be found to have decreased over time and to show a variability related to country.

\section{Materials and methods}

We carried out four prospective, observational, multicenter international studies, in 1998 [14], 2004 [15], 2010 [16], and 2016 (first report), in adults who had need of invasive mechanical ventilation for more than $12 \mathrm{~h}$, or received NPPV for more than $1 \mathrm{~h}$ from ICU admission. The decision to use NPPV was based on the local practices of the units participating in the study. We followed the same methodology for all studies (descriptions of the variables collected in each study are provided in eTable 1). Briefly, in all studies, we collected data on baseline characteristics [age, sex and severity at admission estimated by Simplified Acute Physiology Score (SAPS II) which ranges from 0 (lower severity) to 163 (higher severity)], daily gas exchange, variables related to management ventilator settings, sedation, neuromuscular blockers, and complications [acute respiratory distress syndrome

\section{Take-home message}

The mortality of mechanically ventilated patients could show country-related variability, albeit decreasing over time.

(ARDS), sepsis, ventilator-associated pneumonia]. Evaluation of organ function (cardiovascular, renal, hepatic, hematologic) was performed according to the sequential organ failure assessment (SOFA) score and organ failure was defined as a SOFA sub-score higher than two points for the organ in question. These data were collected while patients were ventilated or until day 28 . Ventilator-free days were calculated according to a previously published formula [26]. Patients were followed until discharge from hospital. In the event of discharge from hospital before day 28 after starting mechanical ventilation, the status on this day was registered.

National coordinators recruited local investigators from eligible ICUs (see full list of Investigators in the Electronic Supplementary Material). Only the research team members at each site were aware of the purpose and the precise timing of the study. Ethics Committees of each participating institution approved the protocol; a waiver of informed consent was obtained according to local regulations.

For the 1998 and 2004 studies, all investigators and research coordinators were provided with a manual describing data collection and definitions, and case report forms on paper. Investigators filled out a case report form for each included patient and sent it to the Coordinating Center to be included in an electronic database. Three study coordinators checked each case report form to identify errors, and inconsistent data were corrected. In the 2010 and 2016 studies, detailed instructions were available through a secure website. Validity checks were made at the time of electronic data entry, including plausibility checks within each variable and between variables. At the time of data entry, the site investigators were required to answer all queries raised by the case report form before they could electronically complete each individual patient data set. Patient data sets that were not complete were not included in the analysis. In addition, prior to analysis, all data were screened for potentially erroneous data and outliers. These data were verified and corrected by site investigators. There was no on-site data monitoring. We followed the Strengthening the Reporting of Observational Studies in Epidemiology (STROBE) statement guidelines for observational cohort studies [27].

\section{Statistical analysis}

The main objective of the analysis was to evaluate, over time, the inter-country variability in 28 -day mortality 
after the start of mechanical ventilation. The first step was to estimate the crude temporal trends of mortality over the four periods by creating a logistic regression model with study year, coded as a dummy variable, as the only independent variable, and 28-day mortality as the dependent variable. To adjust this estimate, we then fitted a multilevel (patients and countries) logistic regression model accounting for baseline demographic variables (age, sex, SAPS II, and reason for initiation of mechanical ventilation); variables related to the evolution of patients over the course of mechanical ventilation [development of organ failure (cardiovascular, renal, hepatic, and hematologic) defined as a SOFA score higher than two points]; complications during the course of mechanical ventilation, such as acute respiratory distress syndrome, sepsis, and ventilator-associated pneumonia; variables related to the ventilatory setting [use of NPPV, a lung-protective strategy (arbitrarily defined as tidal volume below $6 \mathrm{ml} / \mathrm{kg}$ actual body weight or tidal volume below $8 \mathrm{ml} /$ $\mathrm{kg}$ actual body weight plus plateau or peak inspiratory pressure less than $30 \mathrm{cmH}_{2} \mathrm{O}$ )]; and variables related to ventilator management (use of sedation, neuromuscular blocking, and performance of tracheotomy). The random part of the model included two effects and their possible correlation: a random effect in the intercept modeling heterogeneity of mortality among countries in the first study, and a random effect in the slope modeling heterogeneity of changes in mortality over time among countries. The model was estimated by maximum likelihood using the adaptive Gaussian quadrature approximation (with seven quadrature points) [28]. The likelihood ratio test was used to assess the goodness of fit and to compare alternative models. The measure of fixed effects was the odds ratio with $95 \%$ confidence interval. Second, to estimate the random variability of outcomes between countries, we calculated the median odds ratio (MOR) defined as the median value of the odds ratio between the country at highest risk of mortality and the area at lowest risk when randomly picking out two countries. The MOR can be conceptualized as the median increased risk of mortality that a patient would have if he or she moved to a country with a higher risk [29]. For the purpose of this analysis, countries that included fewer than 30 patients were excluded to avoid spurious findings in reliabilityadjusted models. We performed two sensitivity analyses: first, using data from the countries that participated in all four studies, and second, including only patients with invasive ventilation from the beginning of ventilatory support.

A secondary analysis was performed to estimate changes, over time, in the practice of three management strategies: use of NPPV as the first mode of ventilatory support, use of a lung-protective strategy on the first day of mechanical ventilation, and use of sedation (defined as a daily continuous infusion for more than three consecutive hours of any sedative drug) over the course of mechanical ventilation. For this purpose, a multivariate logistic regression model was performed for each management strategy. Variables entered in these models were: age, sex, SAPS II, and reason for starting mechanical ventilation. We calculated and plotted the margin probability for each strategy in each study year with the estimators obtained from the model.

To estimate how these changes influence mortality, a mediation analysis was performed. The mediation analysis assumes a causal relationship between the exposure (period of time) and mediator variables (NPPV, sedation, lung-protective strategy) which in turn may affect the outcome (28-day mortality), and it clarifies the nature of the relationship between the exposure and mediator to better understand the pathways by which the exposure potentially affects the outcome [30]. Therefore, we performed the mediation analysis using the inverse odds ratio weighting method to estimate the direct effect of time on 28-day mortality and the effect, on 28-day mortality, that is mediated by the use of NPPV, sedation and the lung-protective strategy (indirect effect). We calculated direct and indirect effects of each period using inverse odds weighting, which is a semi-parametric weight-based approach to mediation analysis, implemented with standard software. This method can accommodate multiple mediators [31, 32]. Standard errors for the indirect effect were estimated using bootstrapping. For this mediation analysis, we considered two clinical approaches: first, in the overall cohort of mechanically ventilated patients; second, taking into account that the application of the above strategies cannot be uniform, since they depend basically on the severity of respiratory failure at initiation of mechanical ventilation. For this reason, we classified the overall cohort into four sub-groups: (a) patients with a $\mathrm{PaO}_{2} / \mathrm{FiO}_{2}$ ratio higher than 300 at the beginning of mechanical ventilation; (b) patients with a $\mathrm{PaO}_{2} / \mathrm{FiO}_{2}$ ratio of between 200 and 300; (c) patients with a $\mathrm{PaO}_{2} / \mathrm{FiO}_{2}$ ratio of between 100 and 200, and (d) patients with a $\mathrm{PaO}_{2} / \mathrm{FiO}_{2}$ ratio lower than 100 .

Statistical analyses were conducted using Stata Software 14.0 (StataCorp LP, College Station, Texas).

\section{Results}

Overall 27,467 of 63,313 patients (43\%) admitted to participating ICUs met the inclusion criteria in the four periods of study. After excluding patients from countries with fewer than 30 patients, full data for analysis were available for 26,024 patients: 5183 patients in 1998, 4968 patients in 2004, 8108 patients in 2010, and 7765 patients 
in 2016 (eFigure 1). We included patients from 38 countries (eTable 2). The sample size of enrolled patients for each participating country in each study is shown in eTable 3. Fifteen countries (Argentina, Canada, Chile, Colombia, Ecuador, France, Greece, Italy, Mexico, Peru, Portugal, Spain, Tunisia, USA, and Uruguay) had patients in all four studies and accounted for $63.5 \%$ of the overall cohort (16,537 of 26,024 patients).

Comparisons of baseline patient characteristics across studies are shown in Table 1 . Over time, the most common patient type was consistently found to be male, in the sixth decade of life, with a severity at admission that predicted a hospital mortality around 35\%. Changes in the reason for mechanical ventilation were observed, with a decrease in patients with chronic obstructive pulmonary disease (COPD) (from 10\% in 1998 to $7 \%$ in
2016; $p<0.001$ ) and cardiac failure (from $10 \%$ in 1998 to $7 \%$ in 2016; $p<0.001)$ and an increase in patients with neurological disease (from $17 \%$ in 1998 to $21 \%$ in 2016; $p<0.001)$.

Data on evolution and outcomes over the course of mechanical ventilation are shown in Table 2 .

\section{Changes over time in management of mechanical ventilation}

It emerged that there was, over time, a significant increase in the use of the three management strategies, which were found to influence the outcome of ventilated patients: NPPV, lung-protective strategy, and continuous sedation (Table 3 and eFigure 2).

Table 1 Comparison of characteristics of patients at inclusion in each study

$1998(N=5183) \quad 2004(N=4968)$

\begin{tabular}{|c|c|c|c|c|}
\hline Africa & $119(2)$ & $110(2)$ & $167(2)$ & $209(3)$ \\
\hline Asia & - & $78(2)$ & $1214(15)$ & $1764(23)$ \\
\hline Australia \& New Zealand & - & - & $714(9)$ & $193(2)$ \\
\hline Europe & $2387(46)$ & $2133(43)$ & $3392(42)$ & $3337(43)$ \\
\hline Latin America & $1222(24)$ & $1306(26)$ & $1692(21)$ & $1913(25)$ \\
\hline USA \& Canada & $1455(28)$ & $1341(27)$ & $929(11)$ & $349(5)$ \\
\hline Age, mean (SD), years & $59(17)$ & $59(17)$ & $61(17)$ & $62(17)$ \\
\hline Female sex-No. (\%) & 1985(39) & 1967(39) & 3090(38) & 2983(38) \\
\hline \multicolumn{5}{|l|}{ Body weight, kg, mean (SD) } \\
\hline Actual & $72(17)$ & $76(20)$ & $75(20)$ & $74(19)$ \\
\hline$|d e a|^{a}$ & N.r. & $63(10)$ & $62(10)$ & $62(10)$ \\
\hline $\begin{array}{l}\text { Simplified Acute Physiology Score II, mean (SD), } \\
\text { points }^{\text {b }}\end{array}$ & $44(17)$ & $43(18)$ & $45(18)$ & $45(19)$ \\
\hline \multicolumn{5}{|l|}{ Reason for initiation of mechanical ventilation, No. $(\%)^{c}$} \\
\hline Chronic obstructive pulmonary disease & $522(10)$ & $267(5)$ & $523(6)$ & $535(7)$ \\
\hline Asthma & $79(1.5)$ & $63(1)$ & $98(1)$ & $64(1)$ \\
\hline Other chronic pulmonary disease & $60(1)$ & $85(2)$ & $142(2)$ & $158(2)$ \\
\hline Acute respiratory distress syndrome & $231(4.5)$ & $148(3)$ & $280(3)$ & $319(4)$ \\
\hline Postoperative respiratory failure & $1080(21)$ & 1053(21) & $1745(21)$ & $1584(20)$ \\
\hline Cardiac failure & $539(10)$ & $285(6)$ & $616(7.5)$ & $552(7)$ \\
\hline Aspiration & $129(2.5)$ & $139(3)$ & $198(2)$ & $184(2)$ \\
\hline Pneumonia & $721(14)$ & $528(11)$ & $818(10)$ & $873(11)$ \\
\hline Sepsis & $458(9)$ & $449(9)$ & $720(9)$ & $706(11)$ \\
\hline Trauma & $407(8)$ & $284(6)$ & $358(4)$ & $306(4)$ \\
\hline Cardiac arrest & $100(2)$ & $239(5)$ & $470(7)$ & $441(7)$ \\
\hline Other cause of acute respiratory failure & $367(7)$ & $432(9)$ & $503(6)$ & $323(4)$ \\
\hline Neurological disease & $864(17)$ & $938(19)$ & 1565 (19) & $1628(21)$ \\
\hline Neuromuscular disease & $94(2)$ & $58(1)$ & $72(1)$ & $92(1)$ \\
\hline
\end{tabular}

a Ideal body weight was estimated as: Female: $45.5+0.91$ (height - 152.4)/Male: $50+0.91$ (height - 152.4)

b The Simplified Acute Physiology Score II can range from 0 to 163 points. A higher score indicates greater severity

c Because of rounding, percentages may not total 100. In 1998, more than one cause of acute respiratory failure per patient was permitted 
The implementation of NPPV as first ventilatory support increased from $5 \%$ in 1998 to $16 \%$ in 2016 $(p<0.001)$ although without significant changes in the failure rate (around $30 \%$ of patients required intubation in all studies).

The most important change in the management of mechanically ventilated patients was a decrease in the tidal volume (from a mean of $8.8 \mathrm{ml}$ per $\mathrm{kg}$ of actual body weight in 1998 to $6.7 \mathrm{ml}$ per $\mathrm{kg}$ of actual body weight in 2016; $p<0001$ ) and an increment in the applied positive end-expiratory pressure (PEEP) (from a mean of $5 \mathrm{~cm}$ of water in 1998 to $7 \mathrm{~cm}$ of water in 2016; $p<0.001)$. These changes were observed in both patients with ARDS and patients without ARDS (Fig. 1). Also, this evolution implied changes in other relevant variables such as plateau pressure and driving pressure (eFigure 3).

A mixed-effects logistic regression showed the magnitude of these changes, taking as reference the first study, and the inter-country variability (Table 4).

\section{Adjusted analysis of 28-day mortality: inter-country variability}

Raw 28-day mortality by country and study year is shown in eFigure 4 . On average, inter-country variability decreased over time, with countries more distant from the mean changing more in the opposite direction, as shown in Fig. 2.
The bivariate analysis and fitted multilevel logistic regression are shown in eTable 4 . The results of the mixed-effect analysis (eTable 5) showed an independent effect associated with country as estimated by the MOR: 2.02 in 1998 (95\% CI 1.57-2.47); 1.76 (95\% CI 1.47-2.05) in 2004; 1.55 in 2010 (95\% CI 1.36-1.73); and 1.39 (95\% CI 1.24-1.53) in 2016 (Fig. 3).

Also, the sensitivity analysis, including the 15 countries that participated in all four studies, showed similar results in the adjusted model: MOR 1.74 (95\% CI 1.362.11 ) in $1998 ; 1.54$ (95\% CI $1.28-1.79)$ in $2004 ; 1.37$ (95\% CI 1.20-1.54) in 2010; and 1.25 (95\% CI 1.11-1.38) in 2016 (Fig. 3).

The sensitivity analysis including only patients with invasive ventilation from beginning of ventilatory support showed following results: MOR 1.95 (95\% CI 1.522.38 ) in $1998 ; 1.71$ (95\% CI $1.43-1.98)$ in $2004 ; 1.50$ (95\% CI 1.33-1.68) in 2010; and 1.36 (95\% CI 1.21-1.51) in 2016 (Fig. 3).

\section{Influence of management strategies on mortality: mediation analysis}

No effect of mediation variables was found in the overall cohort of patients (eTable 6). However, NPPV, a lung-protective strategy, and the use of sedation showed different effects on mortality according to severity of hypoxemia (eTable 7). In patients with hypoxemia, implementation of a lung-protective strategy had an indirect effect over

Table 2 Comparison of events emerging over the course of mechanical ventilation and outcomes

Events $^{a}$

\begin{tabular}{|c|c|c|c|c|}
\hline Barotrauma, No. (\%) & $154(3)$ & $157(3)$ & $140(2)$ & $51(1)$ \\
\hline Acute respiratory distress syndrome, No. (\%) & $218(4)$ & $279(6)$ & $495(6)$ & $508(6.5)$ \\
\hline Acquired ICU pneumonia, No. (\%) & $438(8)$ & $265(5)$ & $359(4)$ & $107(1)$ \\
\hline Sepsis, No. (\%) & $457(9)$ & $400(8)$ & $1472(18)$ & $1177(15)$ \\
\hline Cardiovascular failure, No. (\%) & $1145(22)$ & $1193(24)$ & $3138(39)$ & $3510(45)$ \\
\hline Acute renal failure, No. (\%) & $971(19)$ & $948(19)$ & $1771(22)$ & $1510(19)$ \\
\hline Hepatic failure, No. (\%) & $326(6)$ & $691(14)$ & $554(7)$ & $139(2)$ \\
\hline Hematological failure, No. (\%) & $552(11)$ & $795(16)$ & $662(8)$ & $419(5)$ \\
\hline \multicolumn{5}{|l|}{ Outcomes } \\
\hline Duration of ventilatory support, median (interquartile range), days & $4(2-8)$ & $6(3-11)$ & $5(3-10)$ & $5(3-9)$ \\
\hline Ventilator-free days, median (interquartile range) & $20(0,25)$ & $17(0,23)$ & $19(0,24)$ & $20(0,25)$ \\
\hline Duration of ICU stay, median (interquartile range), days & $7(4-14)$ & $8(4-15)$ & $7(4-14)$ & $8(4-14)$ \\
\hline ICU mortality, No. (\%) & $1590(31)$ & $1533(31)$ & $2255(28)$ & $2238(29)$ \\
\hline 28-day mortality, No. (\%) & $1719(33)$ & $1605(32)$ & $2432(30)$ & $2072(27)$ \\
\hline Hospital mortality ${ }^{b}$, No. (\%) & $1876(40)$ & $1759(37)$ & $2718(35)$ & $2617(36)$ \\
\hline
\end{tabular}

a With the exception of barotrauma, every event had to meet the relevant diagnostic criteria for at least two consecutive days

b Patients whose date of and status at discharge from hospital were unknown were not included in the calculation (465 patients in 1998,211 patients in 2004,377 patients in 2010, and 570 in 2016) 
Table 3 Changes over time in management of mechanical ventilation and mixed-effects logistic regression analysis to estimate the magnitude of changes

\begin{tabular}{|c|c|c|c|c|}
\hline Variable & $1998(N=5183)$ & $2004(N=4968)$ & $2010(N=8108)$ & $\begin{array}{l}2016 \\
(N=7765)\end{array}$ \\
\hline $\begin{array}{l}\text { Non-invasive positive-pressure ventilation as first mode of ventilatory } \\
\text { support, No. (\%) }\end{array}$ & $256(5)$ & $479(10)$ & $1166(14)$ & $1225(16)$ \\
\hline Use of continuous sedation, No. (\%) & $3164(61)$ & $3486(70)$ & $5723(71)$ & $5605(72)$ \\
\hline Neuromuscular blockers, No. (\%) & $686(13)$ & $524(10.5)$ & $886(11)$ & $803(10)$ \\
\hline Mean tidal volume, mean (SD), $\mathrm{ml} / \mathrm{kg}$ ideal body weight & N.r. & $9.1(2.4)$ & $8.1(1.9)$ & $7.9(1.8)$ \\
\hline Mean tidal volume, mean (SD), $\mathrm{ml} / \mathrm{kg}$ actual body weight & $8.8(2.1)$ & $7.6(2.1)$ & $7.1(1.8)$ & $6.7(1.8)$ \\
\hline $\begin{array}{l}\text { Percentage of days with tidal volume less than } 6 \mathrm{ml} / \mathrm{kg} \text { Actual Body } \\
\text { Weight (ABW) }\end{array}$ & $7 \%$ & $17 \%$ & $20 \%$ & $30 \%$ \\
\hline Mean applied positive end-expiratory pressure, mean (SD), cm of water & $5(3)$ & $6(4)$ & $7(3)$ & 7 (3) \\
\hline $\begin{array}{l}\text { Percentage of days with positive end-expiratory pressure higher than } \\
10 \mathrm{~cm} \text { of water }\end{array}$ & $7 \%$ & $11 \%$ & $30 \%$ & $21 \%$ \\
\hline
\end{tabular}

time (taking first study as reference) in patients with a $\mathrm{PaO}_{2} / \mathrm{FiO}_{2}$ ratio of between 100 and 200; 13.1\%, 10.5\% and 22.6\%, in 2004, 2010 and 2016, respectively; and in patients with a $\mathrm{PaO}_{2} / \mathrm{FiO}_{2}$ ratio lower than 100: $12.7 \%$, $13.5 \%$ and $9.2 \%$, respectively. Meanwhile, the use of sedation had an indirect effect on 28-day mortality over time in those patients with $\mathrm{PaO}_{2} / \mathrm{FiO}_{2}$ ratio higher than 300: $11.9 \%, 24.7 \%$ and $20.8 \%$, in 2004, 2010, and 2016, respectively. The use of NPPV had no indirect effect on 28-day mortality.

\section{Discussion}

We showed that 28-day mortality in an overall cohort of mechanically ventilated patients decreased significantly over time. Our analysis suggests that mortality could show an effect of country, independently of patient and management factors. However, some management strategies (lungprotective strategy and sedation) mediated an important fraction of the effect of temporal evolution on mortality.

Over the past 20 years, an extensive body of research in different areas has led to advances in mechanical ventilation to improve oxygenation and prevent ventilatorinduced lung injury [33]. The question is whether or

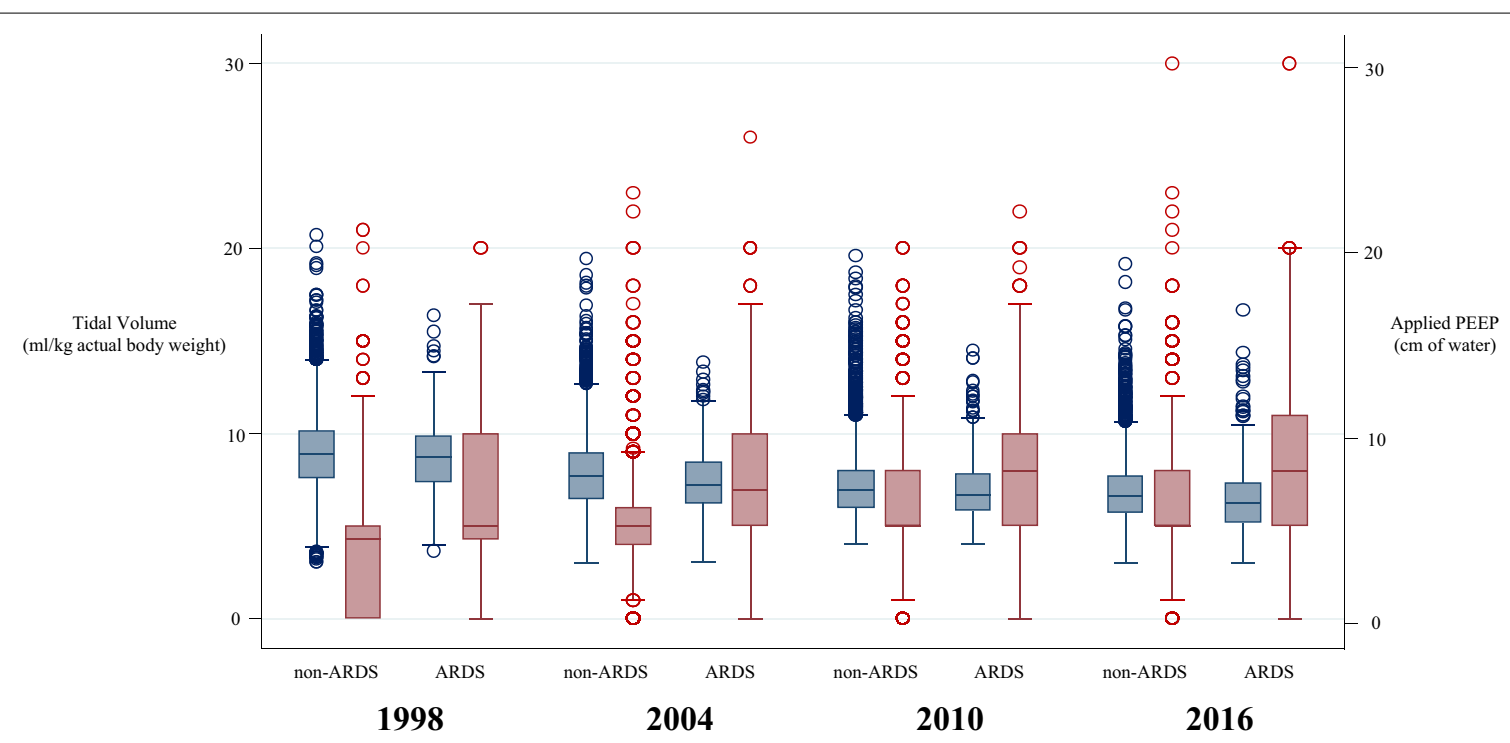

Fig. 1 Changes over time in tidal volume (blue box plot) and positive end-expiratory pressure (red box plot) set at initiation of mechanical ventilation in patients without criteria of acute respiratory distress syndrome (ARDS) and patients with ARDS. For each box plot, the middle line represents the median, the lower hinge represents the first quartile, the upper hinge represents the third quartile, the whiskers extend to 1.5 times interquartile range, and the outliers are values outside the whiskers' range 
Table 4 Odds ratio for the implementation of management strategies (the 1998 study was taken as reference) and the inter-country variability

\begin{tabular}{llccc} 
Variable & \multicolumn{2}{l}{ Odds ratio (95\% confidence interval) } & $\begin{array}{l}\text { Country-level vari- } \\
\text { ability (median odds } \\
\text { ratio) }\end{array}$ \\
\cline { 2 - 5 } & $\mathbf{2 0 0 4}$ & $\mathbf{2 0 1 0}$ & $\mathbf{2 0 1 6}$ & 1.40 \\
$\begin{array}{l}\text { Non-invasive positive-pressure } \\
\text { ventilation }\end{array}$ & $2.15(1.97-2.35)$ & $3.01(2.77-3.27)$ & $3.76(3.45-4.09)$ & 2.09 \\
$\begin{array}{l}\text { Lung-protective strategy } \\
\text { Sedation }\end{array}$ & $2.42(2.06-2.85)$ & $3.60(3.10-4.19)$ & $3.90(3.35-4.54)$ & 2.82 \\
\hline
\end{tabular}

a Defined as a tidal volume below $6 \mathrm{ml} / \mathrm{kg}$ actual body weight or a tidal volume below $8 \mathrm{ml} / \mathrm{kg}$ actual body weight plus plateau or peak inspiratory pressure less than $30 \mathrm{cmH}_{2} \mathrm{O}$

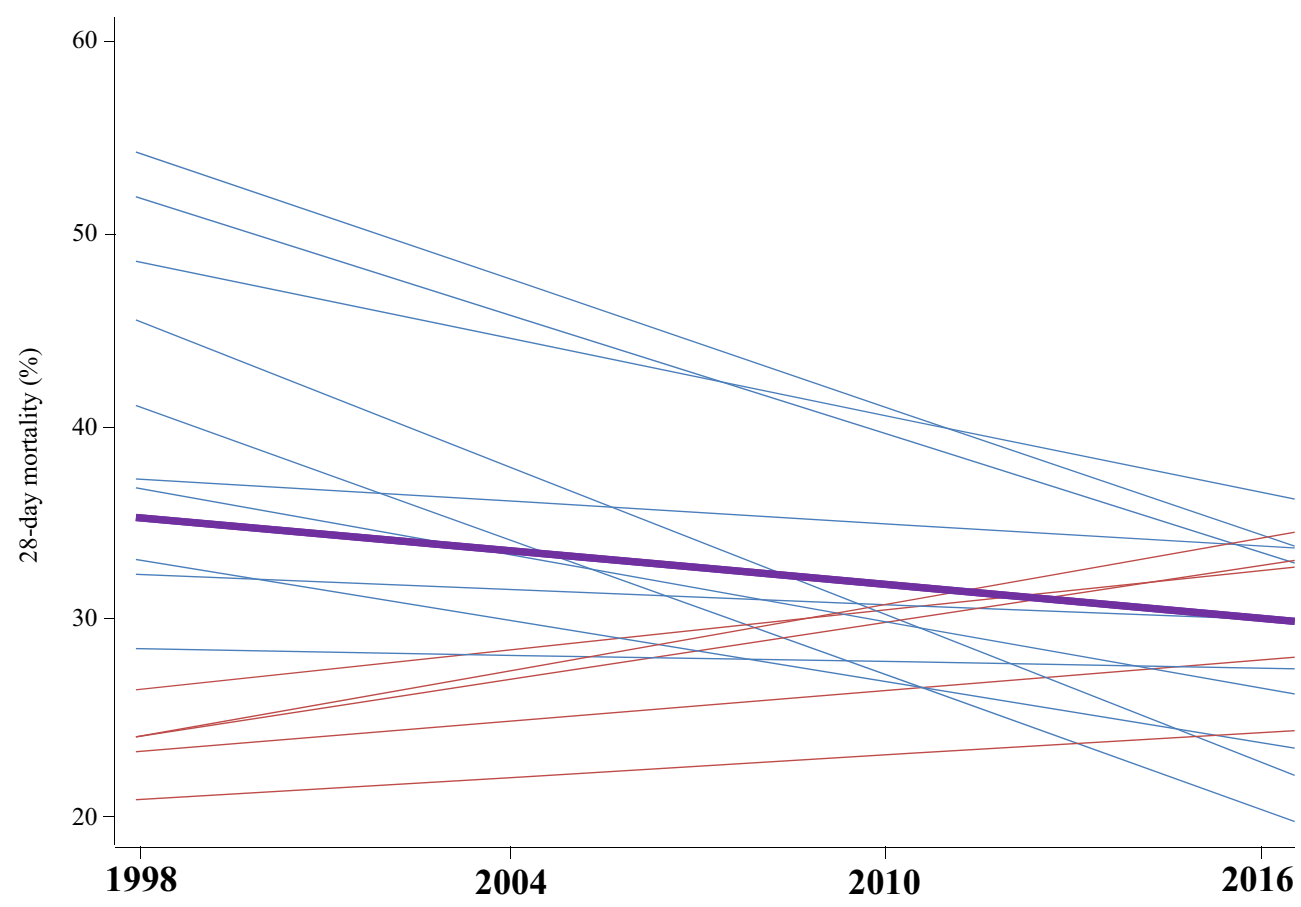

Fig. 2 Regression lines of the evolution of the 28-day mortality by countries (thin lines) and globally (thick line). For simplicity of the graph, only the fifteen countries that participated in the four studies are shown. Overall 28-day mortality decreased over time (thick line). The variability between countries declined (the dispersion is lower in the last year than in the first year). The rate of change in mortality in each country is inversely related to the initial dispersion: countries farthest from the average changed faster in the opposite direction. Countries with initial higher mortality tended to see this decline more rapidly (blue lines), while those with initial lower mortality tended to raise it slowly (red lines)

not the implementation of better practices in the management of mechanically ventilated patients [1-12] has spread homogeneously across the world and whether these strategies themselves have an impact on mortality. We think that a reasonable way to address these issues could be through a proper estimate of the influence of country on mortality rates in mechanically ventilated patients.

Our objective was to evaluate whether the observed variations in mortality of mechanically ventilated patients have an inter-country effect after proper adjustment for variables associated with clinical management. However, our aim was not to make an explicit comparison between individual countries or geographical areas, as other authors have done [17]. Interestingly, we found that the variability in 28-day mortality may be partially explained by a random effect of country and that this effect showed a significant reduction over time. Our results also showed a significant geographical variability in 28 -day mortality among countries, with the risk of death found to differ up to twofold between any two randomly selected countries. The observed random effect of the international variability in mortality could, itself, be influenced by possible unmeasured variables such as ICU organization and utilization [34, 35], intensive-care resources [36], intensivecare admissions policy, intensivist staffing schedules [37], 


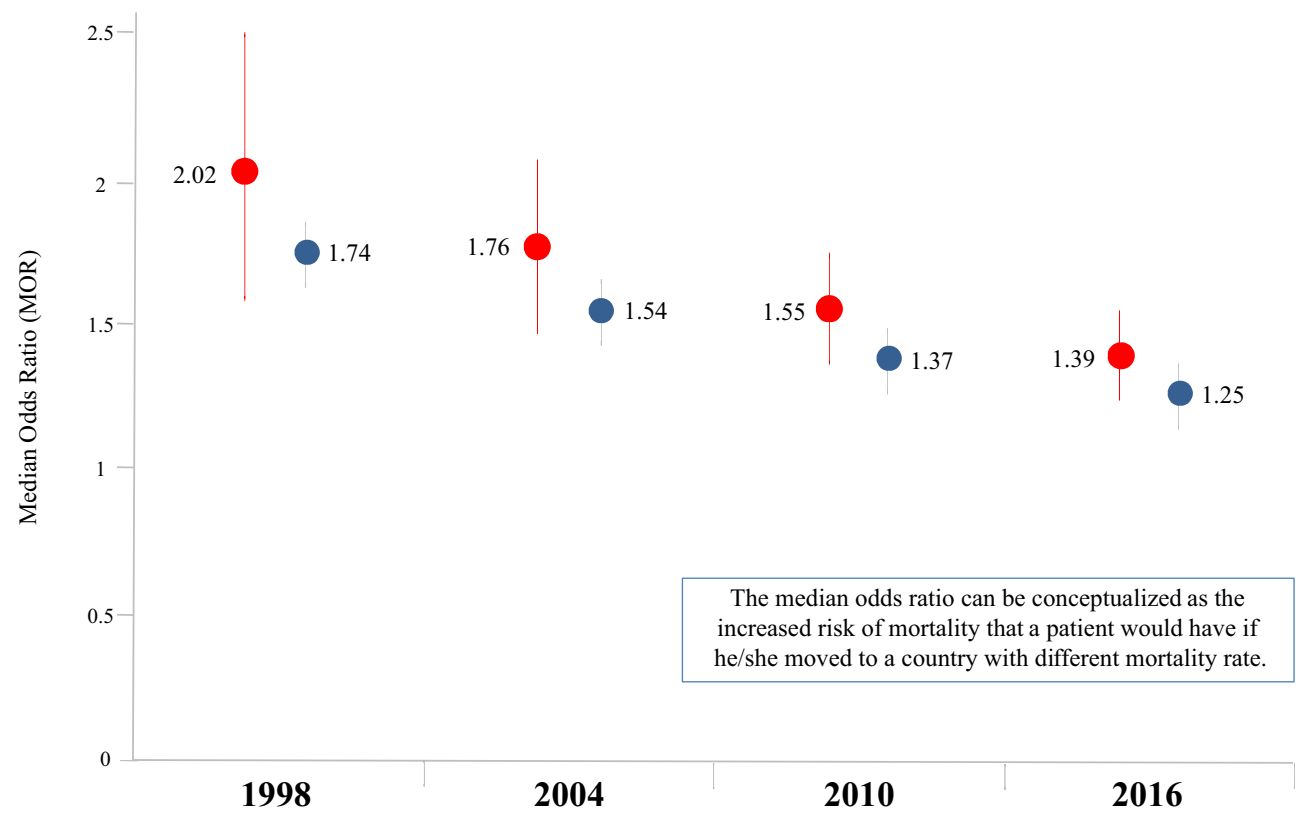

Fig. 3 Adjusted inter-country variability estimated by mean odds ratio ( $95 \%$ confidence interval) at each study year in all the participating countries (red) and in the 15 countries that took part in all four studies (blue). The Median Odds Ratio (MOR) is defined as the median value of the odds ratio between the area at highest risk of mortality and the area at lowest risk when randomly picking out two areas

or variability in the withdrawal of life-sustaining treatment across countries [38, 39]. Additional studies are needed to evaluate whether all these variables, together with the variables assessed in our study, could contribute to that effect.

We speculate that progressive and overall implementation of the best available clinical practice may have led to this variability in mortality [40]. We could argue that the countries with worse results in the past have improved their clinical practice through higher rates of adherence to best practices more experience [41], or an economic improvement in the case of the low- or middle-income countries if we consider the geo-economy a variable associated with the outcome of the overall cohort of mechanically ventilated patients as described in patients with ARDS [17].

However, it is possible to argue that the implementation of certain management strategies, such as NPPV, protective ventilation and sedation, could, per se, be the reason for the observed changes in mortality. A metaanalysis that included individual patient data from nine randomized clinical trials showed that reductions in the daily fluid balance, plateau pressure and tidal volume, and the increase in PEEP decreased the mortality rate in ARDS patients over a period of 17 years [42]. We performed a mediation analysis to evaluate the effect of the aforementioned management strategies. Despite the methodological complexity, we have found a moderate (lower than 25\%) mediated effect of lung-protective strategy and sedation in a subgroup of patients with moderate hypoxemia.

Our study has limitations. Despite enrolling a large number of ICUs from around the world, our sample may not have avoided a selection bias liable to limit the generalizability of its findings. However, given that $60 \%$ of our sample was collected from countries that participated in all four studies, as well as the fact that it covered a time span of almost 20 years, its results can be considered very consistent and reliable. It may also be questioned whether the participating ICUs are sufficiently representative of the countries. We are confident that the availability and use of health resources within each country, including the socioeconomic and demographic aspects of patients, showed similar random distribution. Another limitation is that we did not have all the same ICUs participating in all four studies. To some extent, this was unavoidable due to closure of some previously participating hospitals, changes in resources available for data collection at participating centers, and our goal to expand the representability of the results by including ICUs from more countries. Finally, we had missing data for some relevant variables; however, we believe that the size of the database should have minimized the influence of the missing information in the results. In this sense, we analyzed the evolution over time of tidal volume expressed as the tidal volume in milliliters per kilogram 
of actual body weight, because height was not registered in the first study. Some may argue that the data on tidal volumes are difficult to interpret given the use of actual body weight instead ideal body weight. However, the differences between actual body weight and ideal body weight were found to decrease slightly over time (13.69 kg in 2004, $12.91 \mathrm{~kg}$ in 2010 , and $11.97 \mathrm{~kg}$ in 2016), which resulted in only minor differences between tidal volume estimated by actual or predicted body weight (1.46 $\mathrm{ml}$ in 2004, 1.14 in 2010, and 1.13 in 2016). Therefore, we consider that this possible limitation does not invalidate our observation about the evolution of tidal volume.

In conclusion, we have provided clinical evidence on the observed decrease in mortality of mechanically ventilated patients over a period of 18 years. We observed a variability associated with country, which also decreased over time, but could be partially mediated by the implementation of some management strategies in patients with moderate hypoxemia.

\section{Electronic supplementary materia}

The online version of this article (https://doi.org/10.1007/s00134-019-05867-9) contains supplementary material, which is available to authorized users.

\begin{abstract}
Author details
1 Hospital Universitario de Getafe, Centro de Investigación en Red de Enfermedades Respiratorias (CIBERES), Carretera de Toledo km 12, 50028905 Madrid, Spain. ${ }^{2}$ Unidad de Bioestadística, Clinica Hospital Ramón y Cajal, Instituto Ramón y Cajal de Investigaciones Sanitarias (IRYCIS), Centro de Investigación en Red de Epidemiología y Salud Pública (CIBERESP), Madrid, Spain. ${ }^{3}$ Hospital de la Santa Creu i Sant Pau, Barcelona, Spain. ${ }^{4}$ Medizinische Hochschule Hannover, Hannover, Germany. ${ }^{5}$ Peking Union Medical College Hospital, Beijing, People's Republic of China. ${ }^{6}$ University Hospital of Poitiers, Poitiers, France. ${ }^{7}$ Hospital Nacional Alejandro Posadas, Buenos Aires, Argentina. ${ }^{8}$ Clínica Medellín and Universidad Pontificia Bolivariana, Medellín, Colombia. ${ }^{9}$ Interdepartmental Division of Critical Care Medicine, Toronto, ON, Canada. ${ }^{10}$ Hospital Regional $1^{\circ}$ de Octubre, Instituto de Seguridad y Servicios Sociales de los Trabajadores del Estado (ISSSTE), Mexico, DF, Mexico. ${ }^{11}$ Pulmonary Research Laboratory, Federal University of Juiz de Fora, Juiz De Fora, Brazil. ${ }^{12}$ Hospital Universitario Sao Jose, Belo Horizonte, Brazil. ${ }^{13}$ Hospital Universitario de Montevideo, Montevideo, Uruguay. ${ }^{14}$ Università degli Studi G. d'Annunzio Chieti e Pescara, Chieti, Italy. ${ }^{15}$ Department of Critical Care Medicine, Flinders University, Adelaide, SA, Australia. ${ }^{16}$ Bombay Hospital Institute of Medical Sciences, Mumbai, India. ${ }^{17}$ Istanbul Faculty of Medicine, Istanbul, Turkey. ${ }^{18}$ Center for Clinical Epidemiology of Samsung Medical Center, Seoul, South Korea. ${ }^{19}$ Hospital Fattouma Bourguina, Monastir, Tunisia. ${ }^{20}$ Hospital de Especialidades Eugenio Espejo, Quito, Ecuador. ${ }^{21}$ Papageorgiou Hospital, Thessaloniki, Greece. ${ }^{22}$ Centre Hospitalier Universitarie Ibn Sina, Mohammed V University, Rabat, Morocco. ${ }^{23}$ Faculty of Medicine Ramathibodi Hospital, Mahidol University, Bangkok, Thailand. ${ }^{24}$ South Texas Veterans Health Care System, University of Texas Health Science Center, San Antonio, TX, USA.
\end{abstract}

\section{Acknowledgements}

To all national coordinators and participants in the four International Studies on Mechanical Ventilation listed in Electronic Supplementary Material.

\section{Author contributions}

$\mathrm{OP}, \mathrm{FF}-\mathrm{V}$, as principal investigators, had full access to all the data in the study and take responsibility for the integrity of the data and the accuracy of the data analysis. Study concept and design: OP, FF-V, AA, and AE. National Coordination for the acquisition of data and accuracy of data: KR, BD, AWT, FR, MG, $L S, M C M, B V P, M A S, N N, S M M, A B, P A, N C, G Y S, F A, M J, D M, A A Z$, YS, and AA.
Statistical analysis: AM, VA. Interpretation of data: OP, AM, VA, FF-V, JM, NDF, and AE. Drafting of the manuscript: OP and FF-V. Critical revision of manuscript: AM, VA, JM, KR, BD, AWT, FR, MG, LS, NDF, MCM, BVP, MAS, NN, SMM, AB, PA, NC, GYS, FA, MJ, DM, AAZ, YS, AA, and AE. Final approval of manuscript: OP, AM, VA, FF-V, JM, KR, BD, AWT, FR, MG, LS, NDF, MCM, BVP, MAS, NN, SMM, AB, PA, NC, GYS, FA, MJ, DM, AAZ, YS, AA, and AE.

\section{Compliance with ethical standards}

\section{Conflicts of interest}

The authors declare there is no conflict of interest.

\section{Publisher's Note}

Springer Nature remains neutral with regard to jurisdictional claims in published maps and institutional affiliations.

Received: 15 July 2019 Accepted: 12 November 2019

Published online: 7 January 2020

\section{References}

1. Jaber $S$, Lescot T, Futier E, Paugam-Burtz C, Seguin P, Ferrandiere M, Lasocki S, Mimoz O, Hengy B, Sannini A, Pottecher J, Abback PS, Riu B, Belafia F, Constantin JM, Masseret E, Beaussier M, Verzilli D, De Jong A, Chanques G, Brochard L, Molinari N (2016) Effect of noninvasive ventilation on tracheal reintubation among patients with hypoxemic respiratory failure following abdominal surgery: a randomized clinical trial. JAMA 315:1345-1353

2. Lemiale V, Mokart D, Resche-Rigon M, Pène F, Mayaux J, Faucher E, Nyunga M, Girault C, Perez P, Guitton C, Ekpe K, Kouatchet A, Théodose I, Benoit D, Canet E, Barbier F, Rabbat A, Bruneel F, Vincent F, Klouche K, Loay K, Mariotte E, Bouadma L, Moreau AS, Seguin A, Meert AP, Reignier J, Papazian L, Mehzari I, Cohen Y, Schenck M, Hamidfar R, Darmon M, Demoule A, Chevret S, Azoulay E (2015) Effect of noninvasive ventilation vs oxygen therapy on mortality among immunocompromised patients with acute respiratory failure: a randomized clinical Trial. JAMA 314:1711-1719

3. Demoule A, Chevret S, Carlucci A, Kouatchet A, Jaber S, Meziani F, Schmidt M, Schnell D, Clergue C, Aboab J, Rabbat A, Eon B, Guérin C, Georges H, Zuber B, Dellamonica J, Das V, Cousson J, Perez D, Brochard L, Azoulay E (2016) Changing use of noninvasive ventilation in critically ill patients: trends over 15 years in francophone countries. Intensive Care Med 42:82-92

4. Serpa Neto A, Cardoso SO, Manetta JA, Pereira VG, Espósito DC, de Pasqualucci M, Damasceno MC, Schultz MJ (2012) Association between use of lung-protective ventilation with lower tidal volumes and clinical outcomes among patients without acute respiratory distress syndrome: a meta-analysis. JAMA 308:1651-1659

5. Writing Group for the PReVENT Investigators, Simonis FD, Serpa Neto A, Binnekade JM, Braber A, Bruin KCM, Determann RM, Goekoop GJ, Heidt J, Horn J, Innemee G, de Jonge E, Juffermans NP, Spronk PE, Steuten LM, Tuinman PR, de Wilde RBP, Vriends M, Gama de Abreu M, Pelosi P, Schultz MJ (2018) Effect of a low vs intermediate tidal volume strategy on ventilator-free days in intensive care unit patients without ARDS: a randomized clinical trial. JAMA 320:1872-1880

6. Petrucci N, De Feo C (2013) Lung protective ventilation strategy for the acute respiratory distress syndrome. Cochrane Database Syst Rev 28:CD003844

7. Briel M, Meade M, Mercat A, Brower RG, Talmor D, Walter SD, Slutsky AS, Pullenayegum E, Zhou Q, Cook D, Brochard L, Richard JC, Lamontagne F, Bhatnagar N, Stewart TE, Guyatt G (2010) Higher vs lower positive end-expiratory pressure in patients with acute lung injury and acute respiratory distress syndrome: systematic review and meta-analysis. JAMA 303:865-873

8. Guérin C, Reignier J, Richard JC, Beuret P, Gacouin A, Boulain T, Mercier E, Badet M, Mercat A, Baudin O, Clavel M, Chatellier D, Jaber S, Rosselli S. Mancebo J, Sirodot M, Hilbert G, Bengler C, Richecoeur J, Gainnier M, Bayle F, Bourdin G, Leray V, Girard R, Baboi L, Ayzac L (2013) Prone 
positioning in severe acute respiratory distress syndrome. N Engl J Med 368:2159-2168

9. Papazian L, Forel JM, Gacouin A, Penot-Ragon C, Perrin G, Loundou A, Jaber S, Arnal JM, Perez D, Seghboyan JM, Constantin JM, Courant P, Lefrant JY, Guérin C, Prat G, Morange S, Roch A (2010) Neuromuscular blockers in early acute respiratory distress syndrome. N Engl J Med 363:1107-1116

10. Shehabi Y, Bellomo R, Reade MC, Bailey M, Bass F, Howe B, McArthur C, Seppelt IM, Webb S, Weisbrodt L (2012) Early intensive care sedation predicts long-term mortality in ventilated critically ill patients. Am J Respir Crit Care Med 186:724-731

11. Mehta S, Burry L, Cook D, Fergusson D, Steinberg M, Granton J, Herridge M, Ferguson N, Devlin J, Tanios M, Dodek P, Fowler R, Burns K, Jacka M, Olafson K, Skrobik Y, Hébert P, Sabri E, Meade M (2012) Daily sedation interruption in mechanically ventilated critically ill patients cared for with a sedation protocol: a randomized controlled trial. JAMA 308:1985-1992

12. Girard TD, Kress JP, Fuchs BD, Thomason JW, Schweickert WD, Pun BT, Taichman DB, Dunn JG, Pohlman AS, Kinniry PA, Jackson JC, Canonico AE, Light RW, Shintani AK, Thompson JL, Gordon SM, Hall JB, Dittus RS, Bernard GR, Ely EW (2008) Efficacy and safety of a paired sedation and ventilator weaning protocol for mechanically ventilated patients in intensive care (Awakening and Breathing Controlled trial): a randomised controlled trial. Lancet 371:126-134

13. Gattinoni L, Marini JJ, Collino F, Maiolo G, Rapetti F, Tonetti T, Vasques F, Quintel M (2017) The future of mechanical ventilation: lessons from the present and the past. Crit Care 21:183

14. Esteban A, Anzueto A, Frutos F, Alía I, Brochard L, Stewart TE, Benito S, Epstein SK, Apezteguía C, Nightingale P, Arroliga AC, Tobin MJ (2002) Characteristics and outcomes in adult patients receiving mechanical ventilation: a 28-day international study. JAMA 287:345-355

15. Esteban A, Ferguson ND, Meade MO, Frutos-Vivar F, Apezteguia C, Brochard L, Raymondos K, Nin N, Hurtado J, Tomicic V, González M, Elizalde J, Nightingale P, Abroug F, Pelosi P, Arabi Y, Moreno R, Jibaja M, D'Empaire G, Sandi F, Matamis D, Montañez AM, Anzueto A (2008) Evolution of mechanical ventilation in response to clinical research. Am J Respir Crit Care Med 177:170-177

16. Esteban A, Frutos-Vivar F, Muriel A, Ferguson ND, Peñuelas $O$, Abraira V, Raymondos K, Rios F, Nin N, Apezteguía C, Violi DA, Thille AW, Brochard L, González M, Villagomez AJ, Hurtado J, Davies AR, Du B, Maggiore SM, Pelosi P, Soto L, Tomicic V, D'Empaire G, Matamis D, Abroug F, Moreno RP, Soares MA, Arabi Y, Sandi F, Jibaja M, Amin P, Koh Y, Kuiper MA, Bülow HH, Zeggwagh AA, Anzueto A (2013) Evolution of mortality over time in patients receiving mechanical ventilation. Am J Respir Crit Care Med 188:220-230

17. Laffey JG, Madotto F, Bellani G, Pham T, Fan E, Brochard L, Amin P, Arabi Y, Bajwa EK, Bruhn A, Cerny V, Clarkson K, Heunks L, Kurahashi K, Laake JH, Lorente JA, McNamee L, Nin N, Palo JE, Piquilloud L, Qiu H, Jiménez JIS, Esteban A, McAuley DF, van Haren F, Ranieri M, Rubenfeld G, Wrigge H, Slutsky AS, Pesenti A (2017) Geo-economic variations in epidemiology, patterns of care, and outcomes in patients with acute respiratory distress syndrome: insights from the LUNG SAFE prospective cohort study. Lancet Respir Med 5:627-638

18. Berwick DM (2003) Disseminating innovations in health care. JAMA 289:1969-1975

19. Wennberg JE (2002) Unwarranted variations in healthcare delivery: implications for academic medical centres. BMJ 325:961-964

20. Nguyen YL, Perrodeau E, Guidet B, Trinquart L, Richard JC, Mercat A, Jolliet P, Ravaud P, Brochard L (2014) Mechanical ventilation and clinical practice heterogeneity in intensive care units: a multicenter case-vignette study. Ann Intensive Care 4:2

21. Domanski M, Antman EM, McKinlay S, Varshavsky S, Platonov P, Assmann SF, Norman J (2004) Geographic variability in patient characteristics, treatment and outcome in an International Trial of Magnesium in acute myocardial infarction. Control Clin Trials 25:553-562

22. Chaix B, Rosvall M, Merlo J (2007) Assessment of the magnitude of geographical variations and socioeconomic contextual effects on ischaemic heart disease mortality: a multilevel survival analysis of a large Swedish cohort. J Epidemiol Community Heath 61:349-355

23. Schootman M, Lian M, Pruitt SL, Hendren S, Mutch M, Deshpande AD, Jeffe DB, Davidson NO (2014) Hospital and geographic variability in two colorectal cancer surgery outcomes: complications and mortality after complications. Ann Surg Oncol 21:2659-2666

24. Shroyer AL, Quin JA, Grau-Sepulveda MV, Kosinski AS, Yerokun BA, Mitchell JD, Bilfinger TV (2017) Geographic variations in lung cancer lobectomy outcomes: the general thoracic surgery database. Ann Thorac Surg 104:1650-1655

25. Merchant RM, Berg RA, Yang L, Becker LB, Groeneveld PW, Chan PS (2014) Hospital variation in survival after in-hospital cardiac arrest. J Am Heart Assoc 3:e000400

26. Schoenfeld DA, Bernard GR, Network A (2002) Statistical evaluation of ventilator-free days as an efficacy measure in clinical trials of treatments for acute respiratory distress syndrome. Crit Care Med 30:1772-1777

27. Von Elm E, Altman DG, Egger M, Pocock SJ, Gøtzsche PC, Vandenbroucke JP (2007) Strengthening the reporting of observational studies in epidemiology (STROBE) statement: guidelines for reporting observational studies. BMJ 335:806-808

28. Rabe-Hesketh S, Skrondal A (2008) Multilevel and longitudinal modelling using stata. Stata Press, College Station

29. Merlo J, Chaix B, Ohlsson H, Beckman A, Johnell K, Hjerpe P, Råstam L, Larsen K (2006) A brief conceptual tutorial of multilevel analysis in social epidemiology: using measures of clustering in multilevel logistic regression to investigate contextual phenomena. J Epidemiol Community Health 60:290-297

30. Valeri L, Vanderweele TJ (2013) Mediation analysis allowing for exposuremediator interactions and causal interpretation: theoretical assumptions and implementation with SAS and SPSS macros. Psychol Methods 18:137-150

31. Tchetgen Tchetgen EJ (2013) Inverse odds ratio-weighted estimation for causal mediation analysis. Stat Med 32:4567-4580

32. Nguyen QC, Osypuk TL, Schmidt NM, Glymour MM, Tchetgen Tchetgen EJ (2015) Practical guidance for conducting mediation analysis with multiple mediators using inverse odds Ratio weighting. Am J Epidemiol 181:349-356

33. Pham T, Brochard LJ, Slutsky AS (2017) Mechanical ventilation: state of the art. Mayo Clin Proc 92:1382-1400

34. Sakr Y, Moreira CL, Rhodes A, Ferguson ND, Kleinpell R, Pickkers P, Kuiper MA, Lipman J, Vincent JL (2015) The impact of hospital and ICU organizational factors on outcome in critically ill patients: results from the extended prevalence of infection in intensive care study. Crit Care Med 43:519-526

35. Kahn JM, Goss CH, Heagerty PJ, Kramer AA, O'Brien CR, Rubenfeld GD (2006) Hospital volume and the outcomes of mechanical ventilation. N Engl J Med 355:41-50

36. Tarnow-Mordi WO, Hau C, Warden A, Shearer AJ (2000) Hospital mortality in relation to staff workload: a 4-year study in an adult intensive-care unit. Lancet 356:185-189

37. Kerlin MP, Adhikari NK, Rose L, Wilcox ME, Bellamy CJ, Costa DK, Gershengorn HB, Halpern SD, Kahn JM, Lane-Fall MB, Wallace DJ, Weiss CH, Wunsch H, Cooke CR (2017) The effect of nighttime intensivist staffing on mortality and length of stay among intensive care unit patients. Am J Respir Crit Care Med 195:383-393

38. Phua J, Joynt GM, Nishimura M, Deng Y, Myatra SN, Chan YH, Binh NG, Tan CC, Faruq MO, Arabi YM, Wahjuprajitno B, Liu SF, Hashemian SM, KashifW, Staworn D, Palo JE, Koh Y (2015) Withholding and withdrawal of life-sustaining treatments in intensive care units in Asia. JAMA Intern Med 175:363-371

39. Mark NM, Rayner SG, Lee NJ, Curtis JR (2015) Global variability in withholding and withdrawal of life-sustaining treatment in the intensive care unit: a systematic review. Intensive Care Med 41:1572-1585

40. Lilly CM, Swami S, Liu X, Riker RR, Badawi O (2017) Five-year trends of critical care practice and outcomes. Chest 152:723-735

41. Dres M, Austin PC, Pham T, Aegerter P, Guidet B, Demoule A, VieillardBaron A, Brochard L, Geri G (2018) Acute respiratory distress syndrome cases volume and ICU mortality in medical patients. Crit Care Med 46:e33-e40

42. Zhang Z, Spieth PM, Chiumello D, Goyal H, Torres A, Laffey JG, Hong $Y$ (2019) Declining mortality in patients with acute respiratory distress syndrome: an analysis of the acute respiratory distress syndrome network trials. Crit Care Med 47:315-323 